\title{
ATUAÇÃO DO ENFERMEIRO NO PROGRAMA SAÚDE DA FAMÍLIA EM SOBRADINHO II
}

\author{
Arlete Rodrigues Chagas da Costa ${ }^{1}$ \\ Manuela Costa Melo ${ }^{1}$ \\ Marilda Augusto Oliveira ${ }^{1}$ \\ Rosana Nunes Dias'
}

\begin{abstract}
O Programa Saúde da Família (PSF) segue o modelo de atenção à saúde estabelecido pelo Ministério da Saúde baseado na Lei $n .-2177$ de 30.12.98, na qual foi criado e no Decreto $n .-2043$ de 23.02.99, que estabelece as gestões do PSF. A filosofia do Programa baseia-se na doutrina do Sistema Único de Saúde - SUS com o objetivo de buscar a reorganização da prática assistencial em novas bases e critérios, tendo como objetivo o atendimento ao indivíduo no seu contexto familiar.

Todos os profissionais selecionados para trabalhar nas equipes do PSF, em nosso serviço Todavia deve-se salientar que a maior parte da população brasileira encontrada nas periferias está desprovida de assistência à saúde e, com a atuação do Programa Saúde da Família, a comunidade tem uma referência primária à saúde, desafogando outros atendimentos, recebendo tratamento mais igualitário e humanizado.

passaram por um treinamento geral realizado no
\end{abstract} Centro de Desenvolvimento de Recursos Humanos para a Saúde - CEDRUS, em Brasília, abrangendo todas as áreas para que houvesse maior integração das mesmas e conhecimento da metodologia do Programa.

No Distrito Federal, Brasília é o centro Administrativo das Cidades Satélites, onde o Programa vem atuando desde maio 1999.

Sobradinho, uma das cidades Satélites, criada em 1960, tem uma área de 570 km2; fica localizado a 22,1 Km ao nordeste de Brasília com uma população de 168.000 habitantes.

O presente trabalho se restringe ao Sobradinho Oeste, região criada em 1989 por meio do Programa de Assentamento da População de Baixa Renda, conhecida como Sobradinho II .Hoje com dez (10) anos de existência conta com 5.000 famílias instaladas em dezenove quadras e uma população de cerca de 20.000 habitantes, possuindo asfaltamento nas avenidas principais, saneamento básico, rede elétrica, posto policial, escolas públicas , posto de saúde , pequenas indústrias e comércio diversificado.

\section{Atuação do Enfermeiro do PSF/COER (Centro de Orientação e Educação Rural) Sobradinho II}

Na grande maioria das equipes de saúde o enfermeiro é que detém o papel de Coordenador, acumulando várias funções, principalmente, no acompanhamento dos trabalhos dos Agentes Comunitários de Saúde-ACS. A atuação do enfermeiro no PSF desenvolve-se em dois campos essenciais:

Na unidade de Saúde junto à equipe

- Realizar supervisão técnica dos auxiliares de enfermagem;

- Planejar, supervisionar as ações diárias;

- Implantar as rotinas;

- Desenvolver treinamento em serviço para capacitação dos ACS;

1 Enfermeiras do Programa Saúde da Família - Sobradinho II. Brasilia - DF. 
COSTA, Arlete Rodrigues Chagas da et al.

- Facilitar a integração entre os membros da equipe;

- Promover ações de assistência básica , vigilância epidemiológica e sanitária;

- Implantar programas de atenção á criança, adolescente, mulher, adulto idoso , com ênfase na promoção à saúde e prevenção de doenças;

- Contribuir com a vigilância epidemiológica;

- Orientar para preservação do meio ambiente;

- Realizar consultas de enfermagem;

- Realizar reuniões de grupo;

- Manter registro sistemático das atividades desenvolvidas;

- Encaminhar estatística mensal das atividades para a coordenação central através do assistente técnico do PSF;

- Coordenar a consolidação dos dados , selecionando os elementos de diagnósticos.

\section{Na Comunidade}

- Acompanhar os trabalhos dos ACS;

- Realizar visitas domiciliares nos casos que necessitam de procedimentos especiais;

- Promover educação em saúde;

- Desenvolver atividades de promoção, e prevenção em saúde: campanhas de vacinação, prevenção de helmintos, prevenção da dengue, promoção do aleitamento materno e prevenção de DST/ AIDS:

- Identificar e conhecer formas de trabalho das lideranças, serviços e órgãos existentes na comunidade:

- Estimular a organização e participação popular;

- Discutir com a comunidade a filosofia e funcionamento do PSF.

As equipes 2 e 3 do PSF iniciaram suas atividades no mês de julho de 1999, no COER Sobradinho II, em imóvel cedido pela presidente da entidade, tendo como componentes das equipes:

1 Médico;

2 Enfermeiras;

1 Odontóloga;

6 Auxiliares de Enfermagem,

10 Agentes Comunitários de Saúde;

1 Técnica de Higiene Dentária;

1 Auxiliar de Consultório Dentário;

2 AOSD de limpeza.

O trabalho consistiu no cadastramento da família utilizando-se como instrumento um formulário elaborado pela Secretaria de Saúde do Distrito Federal - SES/DF. A metodologia do trabalho foi desenvolvida através da delimitação da área à ser trabalhada, visitas domiciliares composta por dois ACS e uma enfermeira portando identidade funcional .

Inicialmente fazíamos a nossa apresentação e, mediante a autorização da família, dava-se início à coleta dos dados, no ambiente da familiar, preservando a ética e o sigilo.

Através destas visitas obtivemos o produto para elaboração do consolidado, bem como para traçar o perfil epidemiológico da comunidade e maior integração junto à população envolvida.

De posse dos dados encontrados após a realização do cadastramento, consolidamos os achados referentesàs diversas áreas residenciais (AR) e são apresentados a seguir nos Quadros 1 e 2. 
QUADRO 1 - Cadastro das Famílias/Pessoas, Sobradinho II, Brasília DF, 1999.

\begin{tabular}{|l|c|}
\hline Descrição & n \\
\hline Famílias & 2171,0 \\
\hline Pessoas & 9307,0 \\
\hline Média pessoas por família & 4,3 \\
\hline
\end{tabular}

QUADRO 2 - Faixa etária dos moradores, Sobradinho II, Brasília DF, 1999.

\begin{tabular}{|c|c|c|c|c|c|c|c|c|c|}
\hline SEXO & Faixa Etária & AR 12 & Ar 13 & Ar 14 & AR15 & AR 17 & AR 19 & TOTAL & $\%$ \\
\hline \multirow{10}{*}{$\begin{array}{c}\mathbf{M} \\
\mathbf{A} \\
\mathbf{S} \\
\mathbf{C} \\
\mathbf{U} \\
\mathbf{L} \\
\mathbf{I} \\
\mathbf{N} \\
\mathbf{O}\end{array}$} & Menor de 1 ano & 26 & 20 & 22 & 17 & 12 & 16 & 113 & 2,5 \\
\hline & 1 a 4 anos & 99 & 64 & 108 & 64 & 63 & 59 & 457 & 10,1 \\
\hline & 5 a 6 anos & 30 & 55 & 54 & 33 & 27 & 43 & 242 & 5,3 \\
\hline & 7 a 9 anos & 71 & 70 & 74 & 37 & 50 & 63 & 365 & 8,1 \\
\hline & 10 a 14 anos & 147 & 124 & 133 & 67 & 94 & 82 & 647 & 14,3 \\
\hline & 15 a 19 anos & 121 & 123 & 106 & 79 & 85 & 80 & 594 & 13,1 \\
\hline & 20 a 49 anos & 345 & 324 & 389 & 231 & 262 & 284 & 1835 & 40,6 \\
\hline & 50 a 59 anos & 34 & 27 & 31 & 20 & 31 & 17 & 160 & 3,5 \\
\hline & $\begin{array}{l}\text { Mais de } 60 \\
\text { anos }\end{array}$ & 18 & 30 & 19 & 13 & 18 & 14 & 112 & 2,5 \\
\hline & Subtotal & 891 & 837 & 936 & 561 & 642 & 658 & 4525 & 100,0 \\
\hline \multirow{11}{*}{$\begin{array}{c}\mathbf{F} \\
\mathbf{E} \\
\mathbf{M} \\
\mathbf{I} \\
\mathbf{N} \\
\mathbf{I} \\
\mathbf{N} \\
\mathbf{O}\end{array}$} & Menor de 1 ano & 19 & 16 & 29 & 13 & 9 & 9 & 95 & 20 \\
\hline & 1 a 4 anos & 70 & 75 & 105 & 45 & 53 & 57 & 405 & 8,6 \\
\hline & 5 a 6 anos & 40 & 41 & 39 & 36 & 27 & 29 & 212 & 4,4 \\
\hline & 7 a 9 anos & 70 & 65 & 65 & 37 & 41 & 44 & 322 & 6,7 \\
\hline & 10 a 14 anos & 131 & 110 & 121 & 68 & 99 & 94 & 623 & 1,3 \\
\hline & 15 a 19 anos & 140 & 128 & 126 & 71 & 80 & 82 & 627 & 13,1 \\
\hline & 20 a 49 anos & 410 & 404 & 429 & 257 & 318 & 317 & 2135 & 44,6 \\
\hline & 50 a 59 anos & 37 & 40 & 36 & 30 & 23 & 34 & 200 & 4,2 \\
\hline & $\begin{array}{l}\text { Mais de } 60 \\
\text { anos }\end{array}$ & 26 & 34 & 28 & 22 & 24 & 29 & 163 & 3,4 \\
\hline & Subtotal & 943 & 913 & 978 & 579 & 674 & 695 & 4782 & 100,0 \\
\hline & Total & 1834 & 1750 & 1914 & 1140 & 1316 & 1353 & 9307 & \\
\hline
\end{tabular}

Fonte: Consolidado Geral Área Urbana de Sobradinho II.

Pelos dados obtidos pode-se avaliar o perfil da população no que se refere à faixa etária e, a partir daí, desenvolver vários trabalhos dentro dos programas estabelecidos pelo Ministério da Saúde.

QUADRO 3 - Condições de Saúde Referida/Observada - Sobradinho II, Brasília DF, 1999.

\begin{tabular}{|l|r|r|r|r|r|r|r|r|}
\hline DESCRIÇÃO & AR 12 & AR 13 & AR 14 & AR 15 & AR 17 & AR 19 & TOTAL & \multicolumn{1}{c|}{} \\
\hline SADIA & 1.248 & 1.210 & 1.272 & 823 & 908 & 975 & 6.436 & 69 \\
\hline DOENTE & 577 & 529 & 636 & 310 & 399 & 367 & 2.818 & 30 \\
\hline SEQUELA & 9 & 11 & 6 & 7 & 9 & 11 & 53 & 1 \\
\hline TOTAL & $\mathbf{1 . 8 3 4}$ & $\mathbf{1 . 7 5 0}$ & $\mathbf{1 . 9 1 4}$ & $\mathbf{1 . 1 4 0}$ & $\mathbf{1 . 3 1 6}$ & $\mathbf{1 . 3 5 3}$ & $\mathbf{9 . 3 0 7}$ & $\mathbf{1 0 0}$ \\
\hline
\end{tabular}

Observando-se o Quadro acima temos uma visão das condições saúde/doença da comunidade. Das 9307 pessoas cadastradas 6436 são sadias, o equivalente a 69\%, 2818 são portadoras de doenças, equivalente a $30 \%$ e 53 são portadoras de seqüelas, equivalente a $1 \%$. A prevalência está na 
COSTA, Arlete Rodrigues Chagas da et al.

faixa dos 20 a 49 anos, tanto para homens como para mulheres.

QUADRO 4 - Doenças ou Condições Referidas, pela população de Sobradinho II, Brasília DF, 1999.

\begin{tabular}{|l|c|c|c|c|c|c|c|c|}
\hline Descrição & AR 12 & AR 13 & AR 14 & AR 15 & AR 17 & AR 19 & TOTAL & $\%$ \\
\hline HAN & 0 & 0 & 0 & 0 & 0 & 0 & 0 & 0,00 \\
\hline MAL & 0 & 0 & 0 & 0 & 1 & 1 & 2 & 0,08 \\
\hline TB & 0 & 0 & 0 & 0 & 1 & 2 & 3 & 0,11 \\
\hline CHA & 0 & 0 & 0 & 0 & 10 & 5 & 15 & 0,55 \\
\hline NEO & 2 & 1 & 3 & 4 & 2 & 3 & 15 & 0,55 \\
\hline EPI & 9 & 10 & 5 & 2 & 3 & 13 & 42 & 1,55 \\
\hline DME & 6 & 12 & 10 & 5 & 7 & 9 & 49 & 1,81 \\
\hline DEF & 14 & 18 & 5 & 8 & 14 & 8 & 67 & 2,47 \\
\hline GES & 33 & 9 & 13 & 8 & 12 & 12 & 87 & 3,20 \\
\hline DIA & 17 & 25 & 15 & 12 & 19 & 18 & 106 & 4,00 \\
\hline ALC & 20 & 20 & 25 & 13 & 20 & 23 & 121 & 4,47 \\
\hline TAB & 157 & 133 & 115 & 75 & 138 & 132 & 750 & 27,75 \\
\hline ASM & 93 & 68 & 71 & 59 & 91 & 57 & 439 & 16,24 \\
\hline HÁ & 125 & 120 & 110 & 93 & 90 & 91 & 629 & 23,27 \\
\hline OUTROS & 117 & 79 & 98 & 55 & 23 & 5 & 377 & 13,95 \\
\hline TOTAL & $\mathbf{5 9 3}$ & $\mathbf{4 9 5}$ & $\mathbf{4 7 0}$ & $\mathbf{3 3 4}$ & $\mathbf{4 3 1}$ & $\mathbf{3 7 9}$ & $\mathbf{2 7 0 2}$ & $\mathbf{1 0 0 , 0 0}$ \\
\hline
\end{tabular}

No Quadro 4 temos uma indicação dos índices de incidência de doenças apresentadas pela população.

Com estes resultados traçamos metas e iniciamos o atendimento à criança, gestante, adulto, hipertensos, diabéticos, tabagistas e alcoólatras entre outras.

Estão sendo desenvolvidos trabalhos em conjunto com a Fundação Hospitalar do Distrito Federal (FHDF), relacionados a companhas de multivacinação e mutirões de saúde, bem como atuando em conjunto com o centro de saúde da localidade.

No desenvolvimento da programação, foram evidenciadas várias dificuldades, tais como:

- Mentalidade da população pela prioridade em procurar o primeiro atendimento de saúde no Pronto Socorro;

- Desconhecimento da população sobre a importância da atenção básica de saúde;

- Os Cursos de Ensino Superior não estarem preparando os profissionais para atividades generalistas, com habilitação em saúde da família;

- Mudanças de hábitos;

- Flutuação da população.

Observamos, nesta atividade, grande expectativa por parte da comunidade o que gera facilidade para a implantação do Programa, tendo em vista que após as primeiras ações de saúde, a comunidade integrou-se na busca de solucionar seus problemas sociais. Outros elementos importantes foram a decisão governamental, o interesse e compromisso dos profissionais e a articulação entre os serviços.

Todavia deve-se salientar que a maior parte da população brasileira encontrada nas periferias está desprovida de assistência à saúde e, com a atuação do Programa Saúde da Família, a comunidade tem uma referência primária à saúde, desafogando outros atendimentos, recebendo tratamento mais igualitário e humanizado. 